\title{
Desempenho nutricional de bovinos em pastejo durante o período de transição seca-águas recebendo suplementação proteica
}

\author{
Figueiras, J.F. ${ }^{\text {; }}$ Detmann, E. ${ }^{1}$; Valadares Filho, S.C. '; Paulino, M.F. ${ }^{\text {; }}$ Batista, E.D. ${ }^{\text {; }}$ Rufino, L.M.A. ${ }^{\text {; }}$ Valente, T.N.P. ${ }^{2}$; \\ Reis, W.L.S.' e Franco, M.O.'
}

'Departamento de Zootecnia. Universidade Federal de Viçosa. Viçosa. Minas Gerais. Brasil.

2Instituto Federal Goiano. Campus Posse. Posse. Goiás. Brasil.

\section{PalaVRas chaVe adicIONAIS}

Consumo de pasto.

Balanço de nitrogênio.

Status de nitrogênio.

\section{RESUMO}

Objetivou-se avaliar os efeitos do fornecimento de quantidades crescentes de suplemento proteico durante o período de transição seca-águas sobre o consumo, a digestibilidade e sobre aspectos do metabolismo de compostos nitrogenados em bovinos. Foram utilizados cinco novilhos Nelore com peso corporal (PC) inicial de $273 \mathrm{~kg}$, fistulados no rúmen e mantidos individualmente em piquetes de capim-braquiária com 0,34 ha. $\mathrm{O}$ experimento foi estruturado em delineamento em quadrado latino $5 \times 5$. Os tratamentos foram definidos de maneira a suplementar os animais em $0 ; 1,25 ; 2,5 ; 5,0$ e 10,0 g de suplemento por $\mathrm{kg}$ de PC. O suplemento foi composto por farelo de soja, milho, ureia e sulfato de amônio de forma a apresentar $340 \mathrm{~g}$ de proteína bruta $(\mathrm{PB}) / \mathrm{kg}$ de matéria natural. Verificou-se que os consumos de matéria orgânica $(\mathrm{MO}), \mathrm{PB}$ e $\mathrm{MO}$ digerida foram incrementados linearmente $(p<0,01)$ com o aumento no fornecimento de suplemento. Contudo, nenhum efeito foi verificado $(p>0,10)$ sobre o consumo de pasto. A digestibilidade total e ruminal da $M O$ e PB foi incrementada linearmente $(p<0,10)$ à medida que se ampliou a quantidade de suplemento fornecida. $O$ aumento na quantidade de suplemento ampliou linearmente $(p<0,01)$ - balanço de compostos nitrogenados no organismo do animal e no ambiente ruminal e a produção de compostos nitrogenados microbianos no rúmen. A suplementação proteica para bovinos manejados em pastagens durante o período de transição seca-águas não afeta o consumo voluntário de pasto. Observa-se, contudo, ampliação no balanço de compostos nitrogenados e na eficiência de uso do nitrogênio como reflexo de melhorias do status de nitrogênio no organismo animal.

\section{Nutritional performance of grazing cattle during dry-to-rainy transition season with protein supplementation}

\section{SUMMARY}

This experiment aimed to evaluate the effects of different amounts of a protein supplement on intake, digestibility, and metabolic characteristics of nitrogen utilization in cattle during the dry-to-rainy transition period. Five Nellore bulls fitted with rumen cannulae, averaging $273 \mathrm{~kg}$ of body weight (BW), were used. The animals grazed five signal grass paddocks $(0.34 \mathrm{ha})$. The experiment was carried out according to a $5 \times 5$. Latin square design. The treatments consisted of five different amounts of offered supplement: $0,1.25,2.5,5.0$, and $10.0 \mathrm{~g} / \mathrm{kg} \mathrm{BW}$. The supplement was composed by soybean meal, corn grain, urea and ammonium sulphate in order to present $340 \mathrm{~g}$ of crude protein (CP) per $\mathrm{kg}$ as fed. The organic matter $(O M), C P$, and digested $O M$ intakes increased linearly $(p<0.01)$ as the amount of supplement increased. Despite this, there was no effect of supplement amounts $(p>0.10)$ on pasture intake. The total and ruminal digestibility of $O M$ and $C P$ were linearly increased $(p<0.01)$ as supplement amount increased. The increase in the supplement amount increased linearly $(p<0.01)$ the nitrogen balance in the rumen and animal body, and the production of microbial nitrogen in the rumen. Protein supplementation for grazing cattle during dry-to-rainy transition season does not affect pasture intake. Despite this, the supplementation increases the nitrogen balance and the efficiency of nitrogen utilization. This seems to be caused by an improvement on the nitrogen status in the animal metabolism.

\section{INTRODUÇÃO}

Ao longo do ano, as forrageiras sob pastejo sofrem grande influência de variáveis climáticas, o que causa oscilações na quantidade de massa forrageira produzida, bem como na qualidade da forragem disponível ao animal.
Segundo Detmann et al. (2010), durante os períodos com precipitação regular (transição seca-águas, águas e transição águas-seca) a forragem disponível ao pastejo não pode ser considerada estável do ponto de vista nutricional, pois a forma como o crescimento vegetal se altera durante estes períodos e a interação do animal com a massa disponível podem levar a alterações 
marcantes na qualidade do material ingerido. Este comportamento pode causar alterações nos elementos limitantes da dieta e demandar alterações quantitativas e qualitativas no suplemento ofertado aos animais.

De forma particular, no período de transição secaáguas especula-se que após as primeiras chuvas as forragens possam apresentar altas proporções de nitrogênio não proteico na proteína bruta $(\mathrm{PB})$ e alta digestibilidade da matéria orgânica $(\mathrm{MO})$. Neste período, as gramíneas tropicais não seriam consideradas deficitárias em nitrogênio, apresentando, em geral, teores de PB próximos a $100 \mathrm{~g} / \mathrm{kg}$ de matéria seca (MS) (Detmann et al., 2010).

No entanto, gramíneas tropicais sob pastejo raramente podem ser consideradas como dieta balanceada, no senso de se verificarem concentrações de nutrientes e atributos nutricionais perfeitamente condizentes com as proporções definidas pelas exigências dos animais. Segundo levantamento realizado por Detmann et al. (2010), a forragem colhida em pastagens tropicais sob manejo contínuo nos períodos de precipitação regular apresentam relação energia:proteína acima daquelas demandadas pelos animais. Logo, o pasto, enquanto dieta completa, apresenta-se desequilibrado, demandando a adoção de programas de suplementação para a otimização do uso dos recursos nutricionais do pasto e da produção animal.

Incrementos na produção animal com o uso de programas de suplementação durante o período de transição seca-águas têm sido evidenciados (Nascimento et al., 2009; Acedo et al., 2011; Sales et al., 2011). Contudo, estudos voltados à avaliação de características nutricionais e metabólicas em animais suplementados durante este período são ainda escassos em condições tropicais.

Assim, objetivou-se avaliar os efeitos do incremento na quantidade de suplemento proteico para bovinos em pastejo durante o período de transição seca-águas sobre o consumo, a digestibilidade e sobre aspectos do metabolismo dos compostos nitrogenados.

\section{MATERIAL E MÉTODOS}

O experimento foi conduzido no Departamento de Zootecnia da Universidade Federal de Viçosa, Viçosa-MG, entre agosto e outubro de 2009, período que compreendeu a transição entre as estações de seca e de águas.

Foram utilizados cinco novilhos Nelore, não castrados, com peso corporal (PC) médio inicial de $273 \pm 9 \mathrm{~kg}$, fistulados no rúmen, mantidos em piquetes individuais (0,34 ha) formados com capim-braquiária (Brachiaria decumbens Stapf.), com taxa de lotação média ao longo do experimento de 1,78 UA/ha. Os animais tiveram acesso a água em bebedouros individuais e a mistura mineral em cochos cobertos. De forma anexa aos piquetes, localiza-se o curral para o manejo dos animais, no qual se realizavam coletas de fezes, urina, conteúdo ruminal, digesta omasal e sangue, entre outras práticas de manejo.

Os cinco tratamentos avaliados foram definidos de maneira a suplementar os animais em $0 ; 1,25 ; 2,5 ; 5,0$ e
10,0 g de suplemento (em termos de matéria natural) por kg de PC. O suplemento foi composto (com base na matéria natural) por farelo de soja $(588,8 \mathrm{~g} / \mathrm{kg})$, milho $(382,3 \mathrm{~g} / \mathrm{kg})$, ureia $(26,0 \mathrm{~g} / \mathrm{kg})$ e sulfato de amônio $(2,9 \mathrm{~g} / \mathrm{kg})$ de forma a apresentar $340 \mathrm{~g}$ de $\mathrm{PB} / \mathrm{kg}$ de matéria natural.

O experimento foi estruturado e conduzido segundo delineamento em quadrado latino $5 \times 5$, com períodos experimentais com duração de 16 dias cada. Os cinco primeiros dias de cada período experimental foram destinados à adaptação dos animais aos suplementos, sendo que no primeiro dia foi realizada a pesagem dos animais com o propósito de definir a quantidade de suplemento a ser fornecida. Os suplementos foram ofertados em cochos cobertos localizados em cada piquete às 12:00 h de cada dia durante todo o período experimental.

No primeiro dia de cada período experimental quantificou-se a massa de forragem em cada piquete por intermédio do corte rente ao solo de cinco áreas delimitadas por um quadrado de dimensões $0,5 \times 0,5$ $\mathrm{m}$, selecionadas ao acaso em cada piquete. Foram retiradas alíquotas de cada amostra coletada, sendo confeccionadas amostras compostas para cada piquete, as quais foram secas sob ventilação forçada $\left(60^{\circ} \mathrm{C}\right)$ e processadas em moinho de facas $(1 \mathrm{~mm})$. Posteriormente procedeu-se à quantificação do teor de MS (método INCT G-003-1; Detmann et al., 2012). A disponibilidade média durante o experimento foi de 2,83 $\pm 0,26$ t MS/ ha.

No primeiro, quinto e nono dias de cada período experimental foram obtidas amostras da forragem ingerida pelos animais por intermédio de simulação manual de pastejo. Estas amostras foram secas sob ventilação forçada $\left(60^{\circ} \mathrm{C}\right)$ e processadas em moinho de facas (1 e $2 \mathrm{~mm}$ ). As amostras foram posteriormente compostas, com base no peso seco ao ar, por piquete e período experimental. Amostras do suplemento foram coletadas semanalmente.

Para a estimação da excreção fecal utilizou-se dióxido de titânio como indicador externo, o qual foi fornecido na quantidade de $20 \mathrm{~g}$ /dia a cada animal, às 12:00 h, por intermédio da fístula ruminal, entre o primeiro e oitavo dias de cada período experimental. As amostras fecais foram coletadas diretamente do reto dos animais a partir do sexto dia de cada período experimental de acordo com a distribuição: sexto dia 8:00 h e 14:00 h; sétimo dia - 10:00 h e 16:00 h; e oitavo dia -12:00 h e 18:00 h. Neste período foram tomadas amostras de digesta omasal conforme a distribuição: sexto dia - 8:00 h; sétimo dia - 16:00 h; e oitavo dia 12:00 h. A coleta de digesta omasal foi realizada por intermédio de sucção direta utilizando-se kitasato, tubo coletor e bomba de vácuo, sendo obtidos aproximadamente $500 \mathrm{~mL}$ de amostra por horário e por animal. As amostras de fezes e digesta omasal foram secas sob ventilação forçada $\left(60^{\circ} \mathrm{C}\right)$ e processadas em moinho de facas (1 e $2 \mathrm{~mm}$ ). Posteriormente, elaboraram-se amostras compostas, com base no peso seco ao ar, por animal e período experimental.

Para avaliação do $\mathrm{pH}$, da concentração de nitrogênio amoniacal ruminal (NAR) e da concentração 
de ácidos graxos voláteis (AGV; acético, propiônico e butírico), foram realizadas coletas de líquido ruminal no nono dia de cada período experimental. As amostras foram coletadas manualmente às $6: 00 \mathrm{~h}, 12: 00 \mathrm{~h}$, 18:00 h e 24:00 h na interface líquido:sólido do ambiente ruminal, filtradas em gaze e submetidas à avaliação imediata do pH utilizando-se potenciômetro digital. Posteriormente, foram tomadas duas alíquotas. A primeira alíquota de $40 \mathrm{~mL}$ foi fixada com $1 \mathrm{~mL}$ de $\mathrm{H}_{2} \mathrm{SO}_{4}$ (1:1) e congelada $\left(-20^{\circ} \mathrm{C}\right)$ para a quantificação da concentração de NAR. A segunda alíquota de $10 \mathrm{~mL}$ foi mantida sob refrigeração. Ao final do dia, as quatro alíquotas foram combinadas, fixadas com $10 \mathrm{~mL}$ de solução de ácido metafosfórico ( $200 \mathrm{~g} / \mathrm{L})$ e congeladas $\left(-20^{\circ} \mathrm{C}\right)$ para a quantificação da concentração de AGV.

O procedimento para isolamento de microrganismos ruminais a partir de amostras de conteúdo ruminal foi realizado no nono dia do período experimental, sendo a primeira coleta às 12:00 h e a segunda às 18:00 h, seguindo-se os procedimentos descritos por Cecava et al. (1990). As coletas obtidas nos dois horários foram combinadas por animal.

No décimo sexto dia de cada período experimental foram realizadas coletas de urina, na forma de amostra spot, em micção espontânea dos animais, 2 horas antes e 4 horas após o fornecimento do suplemento. As amostras coletadas foram filtradas em gaze e alíquotas de $10 \mathrm{~mL}$ foram separadas e diluídas com $40 \mathrm{~mL}$ de ácido sulfúrico $(0,036 \mathrm{~N})$ e congeladas $\left(-20^{\circ} \mathrm{C}\right)$.

Simultaneamente às coletas de urina foram feitas coletas de sangue via veia jugular, utilizando tubos com vácuo e gel acelerador de coagulação (BD Vacuntainer ${ }^{\circledR}$ SST II Advance). As amostras de sangue foram imediatamente centrifugadas a $2.700 \times \mathrm{g}$ por $20 \mathrm{minu}-$ tos e alíquotas de soro foram congeladas $\left(-20^{\circ} \mathrm{C}\right)$ para posterior quantificação da concentração de nitrogênio ureico (NUS).

As amostras de forragem obtidas por simulação manual de pastejo, fezes, digesta omasal e suplementos (processadas a $1 \mathrm{~mm}$ ) foram avaliadas quanto aos teores de MS (método INCT-CA G-003/1), MO (método INCT-CA M-001/1), PB (método INCT-CA N-001/1) e FDN corrigida para cinzas e proteína (FDNcp; utilizando-se $\alpha$-amilase termoestável e omitindo-se o uso de sulfito de sódio; método INCT-CA F-002/1) de acordo com os métodos analíticos definidos pelo Instituto Nacional de Ciência e Tecnologia em Ciência Animal (INCT-CA; Detmann et al., 2012; tabela I).

As amostras fecais foram avaliadas quanto aos teores de dióxido de titânio segundo método colorimétrico INCT-CA M-007/1 (Detmann et al., 2012). A excreção fecal foi estimada por intermédio da relação entre dose e concentração fecal do indicador externo. As estimativas de consumo de forragem foram obtidas utilizando-se a FDN indigestível (FDNi) como indicador interno, quantificadas por procedimentos de incubação in situ por 288 horas nas amostras processadas a $2 \mathrm{~mm}$ utilizando-se sacos de TNT (método INCT-CA F-008/1; Detmann et al., 2012). As estimativas de fluxo omasal de MS foram obtidas pela relação entre consumo e concentração omasal de FDNi.
Tabela I. Teores médios de matéria seca (MS), matéria orgânica $(\mathrm{MO})$, proteína bruta $(\mathrm{PB})$, fibra em detergente neutro corrigida para cinzas e proteína (FDNcp), proteína insolúvel em detergente neutro (PIDN) e FDN indigestível (FDNi) no pasto e no suplemento (Average contents of dry matter (DM), organic matter (OM), crude protein (CP), neutral detergent fiber corrected for ash and protein (apNDF), neutral detergent insoluble protein (NDIP) and indigestible NDF (iNDF) in pasture and supplement).

\begin{tabular}{lcc}
\hline Item & Pasto $^{4,5}$ & Suplemento \\
\hline $\mathrm{MS}^{1}$ & $308,1 \pm 8,5$ & 885,5 \\
$\mathrm{MO}^{2}$ & $907,3 \pm 1,9$ & 947,1 \\
$\mathrm{~PB}^{2}$ & $113,3 \pm 3,9$ & 379,5 \\
$\mathrm{FDNcp}^{2}$ & $570,8 \pm 9,1$ & 90,6 \\
$\mathrm{PIDN}^{3}$ & $318,2 \pm 21,1$ & 92,0 \\
$\mathrm{FDNi}^{2}$ & $192,7 \pm 4,8$ & 13,4 \\
\hline
\end{tabular}

${ }^{1} \mathrm{~g} / \mathrm{kg}$ de matéria natural; ${ }^{2} \mathrm{~g} / \mathrm{kg} \mathrm{MS} ;{ }^{3} \mathrm{~g} / \mathrm{kg} \mathrm{PB} ;{ }^{4}$ Amostras obtidas por simulação manual de pastejo; ${ }^{5}$ Média \pm erro-padrão da média.

A concentração de NAR no líquido ruminal foi avaliada por técnica colorimétrica (método INCT-CA N-006/1; Detmann et al., 2012). As concentrações obtidas nos diferentes tempos de amostragem foram combinadas por animal, produzindo-se, ao final, um único valor representativo da média diária de concentração de NAR. Combinação similar foi conduzida para os valores de $\mathrm{pH}$ ruminal. As análises de AGV no fluido ruminal foram realizadas por cromatografia líquida de alto desempenho (HPLC).

As amostras de microrganismos ruminais foram avaliadas quanto aos seus teores de MS e PB, conforme descrito anteriormente, e bases púricas, segundo procedimentos descritos por Ushida et al. (1985). As bases púricas foram utilizadas como indicador para estimação da produção ruminal de compostos nitrogenados microbianos (NMIC).

As amostras de urina, depois de descongeladas, foram compostas por animal e período experimental e analisadas quanto aos teores de ureia (método enzimático-colorimétrico; Bioclin ${ }^{\circledR}$ K047), creatinina (método de Jaffé modificado; Bioclin ${ }^{\circledR}$ K016-1) e nitrogênio total (método de Kjeldahl). As amostras de soro sanguíneo, após descongelamento, foram analisadas quanto aos teores de ureia como descrito para as amostras de urina.

O volume total urinário foi avaliado por intermédio da relação entre concentração de creatinina na urina a sua excreção por unidade de PC (Chizzotti et al., 2006).

Os procedimentos estatísticos foram conduzidos por intermédio do procedimento MIXED do SAS (Statistical Analysis System, versão 9.2) considerando-se os efeitos fixos de tratamentos e os efeitos aleatórios de animais e períodos experimentais. Adotou-se 0,10 como nível crítico de probabilidade para o erro tipo I. Após a análise de variância procedeu-se à decomposição ortogonal da soma de quadrados para tratamentos em efeitos de ordem linear, quadrática, cúbica e de quarto grau relativos à quantidade de suplemento fornecida aos animais. 
Tabela II. Médias e erro-padrão da média (EPM) para os consumos voluntários de matéria seca (MS), MS de pasto (MSP), MS de suplemento (MSSup), matéria orgânica (MO), proteína bruta (PB), fibra em detergente neutro corrigida para cinzas e proteína (FDNcp), fibra em detergente neutro indigestível (FDNi), MO digerida (MOD) e FDNcp digerida (FDND) em função da quantidade de suplemento (Means and standard error of the mean (SEM) for the voluntary intake of dry matter (DM), DM of pasture (DMP), DM of supplement (DMS), organic matter (OM), crude protein (CP), neutral detergent fiber corrected for ash and protein (apNDF), neutral detergent fiber indigestible (iNDF), digested OM (DOM) and digested NDF (DNDF) as a function of the amount of supplement).

\begin{tabular}{|c|c|c|c|c|c|c|c|c|c|c|}
\hline \multirow[b]{2}{*}{ Item } & \multicolumn{5}{|c|}{ Quantidade de suplemento (g/kg PC) ${ }^{1}$} & \multirow[b]{2}{*}{ EPM } & \multicolumn{4}{|c|}{$\mathrm{p}$} \\
\hline & 0 & 1,25 & 2,50 & 5,00 & 10,00 & & L & Q & $\mathrm{C}$ & QT \\
\hline & & & & & & $\mathrm{rg} / \mathrm{dia}$ & & & & \\
\hline MS & 5,694 & 5,818 & 6,468 & 7,662 & 8,823 & 0,472 & $<0,001$ & 0,578 & 0,476 & 0,798 \\
\hline MSP & 5,694 & 5,495 & 5,810 & 6,338 & 6,192 & 0,456 & 0,259 & 0,573 & 0,470 & 0,797 \\
\hline MSsup & - & 0,322 & 0,657 & 1,323 & 2,630 & - & - & - & - & - \\
\hline MO & 5,107 & 5,302 & 5,901 & 7,039 & 8,116 & 0,427 & $<0,001$ & 0,496 & 0,497 & 0,836 \\
\hline PB & 0,602 & 0,745 & 0,897 & 1,186 & 1,748 & 0,064 & $<0,001$ & 0,871 & 0,978 & 0,956 \\
\hline FDNcp & 3,150 & 3,297 & 3,341 & 3,822 & 3,635 & 0,271 & 0,155 & 0,290 & 0,535 & 0,758 \\
\hline FDNi & 1,103 & 1,072 & 1,111 & 1,164 & 1,235 & 0,076 & 0,136 & 0,896 & 0,702 & 0,805 \\
\hline MOD & 2,623 & 2,923 & 3,363 & 4,471 & 5,176 & 0,356 & $<0,001$ & 0,276 & 0,444 & 0,974 \\
\hline FDND & 1,821 & 2,031 & 2,024 & 2,412 & 2,028 & 0,241 & 0,524 & 0,159 & 0,619 & 0,643 \\
\hline \multirow[t]{2}{*}{ PB:MOD² } & 230 & 255 & 267 & 265 & 338 & - & - & - & - & - \\
\hline & \multicolumn{10}{|c|}{$\mathrm{g} / \mathrm{kg}$ de $\mathrm{PC}$} \\
\hline MS & 18,8 & 19,3 & 21,7 & 25,1 & 29,3 & 1,5 & $<0,001$ & 0,604 & 0,583 & 0,680 \\
\hline MSP & 18,8 & 18,2 & 19,5 & 20,7 & 20,6 & 1,5 & 0,262 & 0,605 & 0,581 & 0,689 \\
\hline MSsup & - & 1,1 & 2,2 & 4,4 & 8,7 & 0,3 & - & - & - & - \\
\hline FDNcp & 10,5 & 10,9 & 11,3 & 12,5 & 12,1 & 0,9 & 0,151 & 0,320 & 0,653 & 0,883 \\
\hline FDNi & 3,6 & 3,6 & 3,7 & 3,8 & 4,0 & 0,2 & 0,119 & 0,896 & 0,771 & 0,773 \\
\hline
\end{tabular}

${ }^{1}$ Quantidade de suplemento em matéria natural; L, Q, C, QT= Efeitos de ordem linear (L), quadrática (Q), cúbica (C) e de quarto grau (QT) em função da quantidade de suplemento ofertada; ${ }^{2} \mathrm{~g} / \mathrm{kg}$.

\section{RESULTADOS}

Os consumos de MS, MO, PB, e MO digerida (MOD) foram incrementados linearmente $(\mathrm{p}<0,01)$ com o aumento no fornecimento de suplemento (tabela II). Entretanto, os consumos de MS de pasto, FDNcp, FDNi e FDNcp digerida não foram alterados $(p>0,10)$ em função da quantidade de suplemento (tabela II).

Tabela III. Médias e erro-padrão da média (EPM) para os coeficientes de digestibilidade (g/g) total, ruminal e intestinal da matéria orgânica $(\mathrm{MO})$, proteína bruta $(\mathrm{PB})$, fibra em detergente neutro corrigida para cinzas e proteína (FDNcp) e para a concentração dietética de matéria orgânica digerida (MOD; g/kg MS) em função da quantidade de suplemento (Means and standard error of the mean (SEM) for the digestibility coefficients $(\mathrm{g} / \mathrm{g}$ ) total, intestinal, and ruminal of organic matter (OM), crude protein (CP), neutral detergent fiber corrected for ash and protein (apNDF) and the dietary concentration of digested organic matter (DOM; $\mathrm{g} / \mathrm{kg} \mathrm{DM}$ ) as a function of the amount of supplement).

\begin{tabular}{|c|c|c|c|c|c|c|c|c|c|c|}
\hline \multirow[b]{2}{*}{ Item } & \multicolumn{5}{|c|}{ Quantidade de suplemento (g/kg PC) ${ }^{1}$} & \multirow[b]{2}{*}{ EPM } & \multicolumn{4}{|c|}{$\mathrm{p}$} \\
\hline & 0 & 1,25 & 2,50 & 5,00 & 10,00 & & L & Q & $\mathrm{C}$ & QT \\
\hline & & & & & & Total & & & & \\
\hline MO & 0,513 & 0,546 & 0,550 & 0,630 & 0,638 & 0,028 & 0,008 & 0,130 & 0,373 & 0,452 \\
\hline PB & 0,513 & 0,605 & 0,623 & 0,708 & 0,763 & 0,034 & 0,002 & 0,109 & 0,791 & 0,477 \\
\hline FDNcp & 0,577 & 0,612 & 0,580 & 0,627 & 0,558 & 0,031 & 0,565 & 0,229 & 0,674 & 0,335 \\
\hline \multirow[t]{2}{*}{ MOD } & 436 & 489 & 502 & 573 & 605 & 179 & $<0,001$ & 0,041 & 0,817 & 0,371 \\
\hline & \multicolumn{10}{|c|}{ Ruminal $^{3}$} \\
\hline $\mathrm{MO}$ & 0,347 & 0,384 & 0,375 & 0,478 & 0,505 & 0,031 & 0,001 & 0,356 & 0,367 & 0,378 \\
\hline PB & $-0,286$ & 0,118 & 0,026 & 0,273 & 0,421 & 0,108 & 0,009 & 0,145 & 0,444 & 0,132 \\
\hline \multirow[t]{2}{*}{ FDNcp } & 0,550 & 0,579 & 0,554 & 0,639 & 0,566 & 0,030 & 0,583 & 0,108 & 0,265 & 0,308 \\
\hline & \multicolumn{10}{|c|}{ Intestinal $^{2}$} \\
\hline MO & 0,251 & 0,262 & 0,274 & 0,296 & 0,267 & 0,021 & 0,547 & 0,185 & 0,744 & 0,985 \\
\hline PB & 0,600 & 0,535 & 0,576 & 0,594 & 0,589 & 0,030 & 0,620 & 0,876 & 0,222 & 0,290 \\
\hline FDNcp & 0,053 & 0,079 & 0,059 & 0,069 & $-0,034$ & 0,044 & 0,048 & 0,344 & 0,116 & 0,951 \\
\hline
\end{tabular}

${ }^{1}$ Quantidade de suplemento em matéria natural; L, Q, C, QT= Efeitos de ordem linear (L), quadrática (Q), cúbica (C) e de quarto grau (QT) em função da quantidade de suplemento ofertada; ${ }^{2}$ Calculado como fração do que chegou ao local da digestão. 
Tabela IV. Médias e erro-padrão da média (EPM) para o pH ruminal, concentração de nitrogênio amoniacal ruminal (NAR; $\mathrm{mg} / \mathrm{dL}$ ), concentração de ácidos graxos voláteis (AGV; mmol/dL), proporções molares ( $\mathrm{mmol} / 100 \mathrm{mmol}$ ) de acetato, propionato e butirato, e relação acetato:propionato (A:P) no líquido ruminal em função da quantidade de suplemento (Means and standard error of the mean (SEM) for ruminal pH, ruminal ammonia nitrogen (NAR; $\mathrm{mg} / \mathrm{dL}$ ), concentration of volatile fatty acids (VFA; mmol/dL), molar proportion ( $\mathrm{mmol} / 100 \mathrm{mmol}$ ) of acetate, propionate and butyrate, and acetate:propionate ratio $(A: P)$ in the ruminal fluid depending on the amount of supplement).

\begin{tabular}{|c|c|c|c|c|c|c|c|c|c|c|}
\hline \multirow[b]{2}{*}{ Item } & \multicolumn{5}{|c|}{ Quantidade de suplemento (g/kg PC) ${ }^{1}$} & \multirow[b]{2}{*}{ EPM } & \multicolumn{4}{|c|}{$\mathrm{p}$} \\
\hline & 0 & 1,25 & 2,50 & 5,00 & 10,00 & & L & Q & C & QT \\
\hline $\mathrm{pH}$ & 6,81 & 6,78 & 6,81 & 6,70 & 6,59 & 0,04 & 0,006 & 0,708 & 0,519 & 0,438 \\
\hline NAR & 8,49 & 10,73 & 11,52 & 13,58 & 16,96 & 0,64 & $<0,001$ & 0,224 & 0,464 & 0,533 \\
\hline AGV & 8,30 & 9,06 & 9,75 & 8,49 & 8,64 & 0,77 & 0,826 & 0,577 & 0,225 & 0,667 \\
\hline Acetato & 77,36 & 77,02 & 76,96 & 76,72 & 74,36 & 0,72 & 0,008 & 0,369 & 0,690 & 0,935 \\
\hline Propionato & 16,50 & 16,52 & 16,60 & 16,24 & 18,28 & 0,41 & 0,007 & 0,060 & 0,360 & 0,795 \\
\hline Butirato & 6,16 & 6,44 & 6,42 & 7,08 & 7,40 & 0,48 & 0,059 & 0,722 & 0,768 & 0,730 \\
\hline$A: P$ & 4,69 & 4,68 & 4,65 & 4,74 & 4,08 & 0,15 & 0,009 & 0,110 & 0,436 & 0,825 \\
\hline
\end{tabular}

${ }^{1}$ Quantidade de suplemento em matéria natural; L, Q, C, QT= Efeitos de ordem linear (L), quadrática (Q), cúbica (C) e de quarto grau (QT) em função da quantidade de suplemento ofertada.

Tabela V. Médias e erro-padrão da média (EPM) para a concentração de nitrogênio ureico no soro (NUS; $\mathrm{mg} / \mathrm{dL}$ ), consumo de nitrogênio (CN; g/dia), excreção fecal de nitrogênio (EFN; g/dia), excreção urinária de nitrogênio (EUN; g/dia), excreção urinăria de nitrogênio ureico (EUNU; g/dia), balanço nitrogenado aparente (BN; g/dia), balanço nitrogenado relativo (BNR; g/g de nitrogênio ingerido), balanço nitrogenado ruminal (BNRU; g/dia), produção ruminal de nitrogênio microbiano (NMIC; g/dia) e eficiência de síntese de proteína microbiana (EFM; g de PB microbiana/kg de MOD) em função da quantidade de suplemento (Means and standard error of the mean (SEM) for the concentration of serum urea nitrogen (SUN; mg/dL), nitrogen intake (NI; g/day), fecal nitrogen excretion (FNE; g/day), urinary nitrogen excretion (UNE; g/day), urinary excretion of urea nitrogen (UEUN; g/day), apparent nitrogen balance (ANB; g/ day), relative nitrogen balance (RNB; g/g of nitrogen intake), ruminal nitrogen balance (RUNB; g/day), ruminal microbial nitrogen production (MICN; g/day) and efficiency of microbial protein synthesis (EMPS; $g$ of microbial CP/kg of DOM) depending on the amount of supplement).

\begin{tabular}{|c|c|c|c|c|c|c|c|c|c|c|}
\hline \multirow[b]{2}{*}{ Item } & \multicolumn{5}{|c|}{ Quantidade de suplemento (g/kg PC) ${ }^{1}$} & \multirow[b]{2}{*}{ EPM } & \multicolumn{4}{|c|}{$\mathrm{p}$} \\
\hline & 0 & 1,25 & 2,50 & 5,00 & 10,00 & & $\mathrm{~L}$ & $Q$ & C & QT \\
\hline NUS & 9,24 & 12,22 & 12,80 & 16,90 & 22,00 & 0,71 & $<0,001$ & 0,222 & 0,944 & 0,200 \\
\hline $\mathrm{CN}$ & 96,3 & 119,3 & 143,6 & 189,8 & 279,7 & 10,2 & $<0,001$ & 0,871 & 0,978 & 0,956 \\
\hline EFN & 44,6 & 46,4 & 50,1 & 54,4 & 65,1 & 3,8 & 0,001 & 0,972 & 0,986 & 0,824 \\
\hline EUN & 67,7 & 89,4 & 88,1 & 86,8 & 138,5 & 11,7 & 0,001 & 0,403 & 0,197 & 0,675 \\
\hline EUNU & 23,1 & 32,1 & 42,4 & 55,6 & 82,3 & 5,1 & $<0,001$ & 0,521 & 0,804 & 0,808 \\
\hline $\mathrm{BN}$ & $-16,0$ & $-16,5$ & 5,5 & 48,5 & 76,0 & 11,6 & $<0,001$ & 0,322 & 0,185 & 0,690 \\
\hline BNR & $-0,202$ & $-0,182$ & $-0,050$ & 0,260 & 0,250 & 0,092 & 0,009 & 0,091 & 0,179 & 0,884 \\
\hline BNRU & $-22,6$ & 18,3 & 16,9 & 55,5 & 118,3 & 9,9 & $<0,001$ & 0,586 & 0,456 & 0,152 \\
\hline NMIC & 48,2 & 52,3 & 66,0 & 79,5 & 93,4 & 5,1 & $<0,001$ & 0,690 & 0,600 & 0,323 \\
\hline EFM & 117,0 & 112,2 & 129,1 & 112,3 & 107,9 & 10,4 & 0,386 & 0,975 & 0,346 & 0,234 \\
\hline
\end{tabular}

${ }^{1}$ Quantidade de suplemento em matéria natural; L, Q, C, QT= Efeitos de ordem linear (L), quadrática (Q), cúbica (C) e de quarto grau (QT) em função da quantidade de suplemento ofertada.

A ampliação da quantidade de suplemento elevou linearmente $(p<0,01)$ a digestibilidade total e ruminal da $\mathrm{MO}$ e da PB. A concentração de MOD na dieta foi afetada de forma quadrática $(\mathrm{p}<0,05)$ pela quantidade de suplemento. Por outro lado, nenhum efeito da quantidade de suplemento $(p>0,10)$ foi verificado sobre a digestibilidade total e ruminal da FDNcp (tabela III).

Não foram verificados efeitos $(p>0,10)$ dos tratamentos sobre a digestibilidade intestinal da MO e PB. A digestibilidade intestinal da FDNcp foi reduzida de forma linear $(p<0,05)$ com o aumento na quantidade de suplemento (tabela III). Ressalta-se, contudo, que todos os coeficientes de digestibilidade intestinal da FDNcp foram iguais a zero $(p>0,10)$.

$\mathrm{O} p H$ ruminal foi reduzido linearmente $(\mathrm{p}<0,01)$ e a concentração de NAR foi incrementada linearmente $(\mathrm{p}<0,01)$ com o aumento no fornecimento de suplemento (tabela IV).

Embora as concentrações totais de AGV total não tenham sido afetadas $(\mathrm{p}>0,10)$ pela quantidade de suplemento, verificou-se incremento linear na proporção molar de butirato $(\mathrm{p}<0,06)$ e decréscimos lineares $(\mathrm{p}<0,01)$ na proporção molar de acetato e na relação acetato:propionato com o aumento no fornecimento de suplemento. A proporção molar de propionato apresentou comportamento quadrático $(\mathrm{p}<0,07)$ em função da quantidade de suplemento, com valores relativamente estáveis de 0 a $5 \mathrm{~g} / \mathrm{kg}$ PC e com incremento proeminente com o fornecimento de $10 \mathrm{~g} / \mathrm{kg}$ PC em suplemento (tabela IV).

Observou-se incremento linear $(p<0,01)$ na concentração de NUS com o aumento na quantidade de suplemento fornecida (tabela V). 
O aumento na quantidade de suplemento ampliou linearmente $(p<0,01)$ o consumo, a excreção fecal, a excreção urinária e o balanço de compostos nitrogenados no organismo do animal (BN) e no ambiente ruminal (BNRU) e a produção de NMIC. Contudo, nenhum efeito foi verificado sobre a eficiência de síntese de proteína microbiana ( $\mathrm{p}>0,10)$, cujo valor médio observado foi de 115,7 g PB microbiana/kg MOD (tabela V).

\section{DISCUSSÃO}

Neste estudo não foram verificados efeitos positivos da suplementação sobre o consumo voluntário de forragem (tabela II). Este comportamento corrobora os resultados obtidos por outros autores em condições tropicais ao fornecerem suplementos proteicos a bovinos manejados em pastagens durante períodos de crescimento das forrageiras (Costa et al., 2011a; Lazzarini, 2011; Sales et al., 2011).

Resultados de estudos conduzidos no Brasil permitem evidenciar que a inclusão de compostos nitrogenados suplementares na dieta de bovinos alimentados com gramíneas tropicais pode ampliar o consumo de forragem basal até que níveis proteicos próximos a $100 \mathrm{~g} \mathrm{~PB} / \mathrm{kg}$ MS sejam atingidos (Figueiras et al., 2010; Sampaio et al., 2010). A partir desta concentração dietética de $\mathrm{PB}$, as exigências microbianas em termos de compostos nitrogenados seriam atendidas e nenhum estímulo sobre o consumo de material digerido seria mais observado (Detmann et al., 2010), minimizando-se o efeito de enchimento ruminal da forragem basal. Segundo Detmann et al. (2009), concentração mínima de $8 \mathrm{mg}$ NAR/dL seria demandada para que se propicie as condições necessárias para que os microrganismos ruminais possam degradar com eficiência a fibra oriunda da forragem.

Desta forma, considerando-se a concentração média de PB da forragem basal (113 g/kg MS; tabela I) e a concentração de NAR verificada na ausência de suplementos (8,49 mg/dL; tabela IV), não seriam esperados efeitos negativos associados a restrições quanto à degradação da fibra insolúvel sobre o consumo voluntário de forragem. Estes argumentos são corroborados pela ausência de efeitos da suplementação sobre o consumo de FDNcp digerida (tabela III) e sobre o coeficiente de digestibilidade ruminal da FDNcp (tabela IV).

Durante os períodos de franco crescimento da forragem, como no período de transição seca-águas, a forragem disponível ao pastejo constitui dieta com excesso relativo de energia em relação à concentração de proteína (Detmann et al., 2010). Assim, considerando-se que uma relação proteína:energia balanceada constitui fator determinante para maximizar o consumo voluntário (Illius e Jessop, 1996), a adição de energia via suplementação poderia acentuar o desequilíbrio dietético. Isto levaria à ampliação do desconforto metabólico do animal, o qual poderia substituir grande massa de forragem por pequena quantidade de suplemento a fim de equilibrar a relação proteína:energia em seu metabolismo. Ocorrência de efeitos substitutivos devido ao fornecimento de concentrados para bovinos em pastejo durante o período das águas foram relatados por Detmann et al. (2001) e Costa et al. (2011b).

Neste contexto, a adição de concentrado à dieta incrementou a disponibilidade e a ingestão de energia, o que pode ser percebido pelo incremento no consumo e na concentração dietética de MOD (tabelas II e III) e na redução da relação acetato:propionato no ambiente ruminal, a despeito da manutenção da concentração total de AGV (tabela IV). Ressalta-se que estes efeitos são atribuídos única e exclusivamente ao suplemento, pois, como previamente ressaltado, não foram observadas alterações no consumo de pasto e na degradação ruminal da FDN.

Contudo, devido à alta concentração de PB no suplemento (380 g PB/kg MS; tabela I), a ampliação no consumo de energia (i.e., MOD) foi acompanhada por incremento no consumo de PB. Assim, os teores de PB e MOD na dieta foram simultaneamente ampliados, fazendo com que não ocorresse queda na relação proteína:energia (i.e., PB:MOD; tabela II), o que parece ter evitado a ocorrência de efeito substitutivo e propiciado a manutenção do consumo de pasto (tabela II). Em situações de forragem de média a alta qualidade, o fornecimento de suplementos proteicos favorece a manutenção da relação proteína:energia dentro de uma faixa confortável ao animal e compatível com as demandas metabólicas. Isto reitera que a suplementação essencialmente proteica pode ser mais adequada para se maximizar o uso de forragem em animais manejados em pastos tropicais de alta qualidade (Costa et al., 2011b).

De forma geral, os principais benefícios da suplementação parecem residir sobre o incremento na deposição de nitrogênio no corpo animal, mensurada pelo $\mathrm{BN}$, e sobre o incremento na eficiência de uso do nitrogênio dietético, mensurada pelo balanço relativo de compostos nitrogenados (BNR) (tabela V). Comportamento similar foi observado por diferentes autores em condições tropicais (Costa et al., 2011c; Rufino, 2011; Batista, 2012).

A ampliação no fornecimento de suplemento elevou a excreção fecal de nitrogênio (tabela V), o que parece ser reflexo do aumento no escape de amido para o intestino grosso, o que amplia a atividade microbiana naquele sítio, elevando a excreção de nitrogênio metabólico fecal (Ørskov, 1988). Concomitantemente, o aumento no fornecimento de suplemento incrementou as perdas nitrogenadas na urina (tabela V), possivelmente causadas pela maior disponibilidade de nitrogênio no rúmen (tabela IV), o que ocasionou maior transferência de nitrogênio para a corrente sanguínea, ampliando a concentração de NUS e, consequentemente, a perda urinária de nitrogênio total e ureico (tabela V).

Contudo, a despeito da ampliação nas perdas, observou-se efeito linear positivo sobre BN e BNR, o que indica que o aumento na eficiência de utilização do nitrogênio foi mais proeminente que as perdas causadas pelo fornecimento de suplementos. As estimativas de NMIC foram ampliadas linearmente pelo fornecimento de suplementos (tabela V), o que implica em aumento no fornecimento de proteína metabolizável (PM) para o animal. Contudo, considerando-se que nem todo 
NMIC está na forma de proteína verdadeira e que esta proteína não seria totalmente aproveitada pelos processos de digestão intestinal, pode ser percebido que o aumento no suprimento de NMIC não pode responder totalmente pelo aumento na deposição de nitrogênio no organismo animal. Comportamento similar foi relatado por Costa et al. (2011c), Rufino (2011) e Batista (2012).

Incrementos no desempenho nutricional animal com o uso de suplementos têm sido atribuídos a melhorias no status de nitrogênio no organismo animal (Egan, 1965a; Egan e Moir, 1965). O termo status de nitrogênio define a disponibilidade quantitativa e qualitativa de compostos nitrogenados para todas as funções fisiológicas no metabolismo animal, incluindose as funções associadas com o metabolismo de outros compostos (e.g., energia) (Detmann et al., 2014).

Com base no conceito de status de nitrogênio, pode ser estabelecido que os compostos nitrogenados disponíveis para o metabolismo animal seriam utilizados para diferentes funções metabólicas seguindo-se uma ordem de prioridade, a saber: sobrevivência, mantença e produção (crescimento, reprodução, etc). Portanto, deposições de nitrogênio na forma de tecidos corporais ou produtos somente ocorreriam depois de supridas as demandas por compostos nitrogenados com maior prioridade (Detmann et al., 2014).

Uma das funções metabólicas de maior prioridade é a reciclagem de nitrogênio para o trato gastrointestinal. Esta assertiva mostra-se plausível considerando-se que um suprimento contínuo de nitrogênio para o crescimento microbiano no rúmen deve ser visto como estratégia de sobrevivência (Egan, 1965b; Van Soest, 1994).

Sob suprimento deficiente de nitrogênio, o animal reduz a excreção urinária de nitrogênio e incrementa a fração do nitrogênio dietético que é reciclada ao ambiente ruminal (Hennessy e Nolan, 1988). Se a deficiência de nitrogênio se torna mais severa, o animal pode ampliar a mobilização de tecido para sustentar a massa de nitrogênio reciclada (NRC, 1985; Rufino, 2011). Contudo, considerando-se uma situação alimentar na qual não haja deficiência dietética proeminente de compostos nitrogenados, a quantidade de nitrogênio reciclada ao ambiente ruminal mantém-se relativamente constante (Marini e Van Ambourgh, 2003). Portanto, haverá menor deposição de nitrogênio na forma de tecidos sob baixas concentrações dietéticas de compostos nitrogenados devido ao fato de uma maior percentagem do nitrogênio ingerido ser direcionada para reciclagem e, como consequência, menor percentagem do nitrogênio estará disponível para produção.

As questões relacionadas às prioridades metabólicas dos compostos nitrogenados podem ser percebidas, ao menos em parte, a partir da avaliação do BNRU. Na ausência de suplementação, estimativa negativa de BNRU foi obtida (tabela V), o que concorda com os resultados obtidos por diversos autores em condições tropicais (Costa et al., 2011a; 2011c; Rufino, 2011; Batista, 2012). Nestes casos, existirá maior dependência dos eventos de reciclagem para prover suprimento adequado de nitrogênio no ambiente ruminal. Isto acarretará redução da eficiência de utilização da PM para ganho e, em alguns casos, em elevação da taxa de quebra de proteína muscular para o suprimento das demandas de nitrogênio de maior prioridade (Costa et al., 2011b; Rufino, 2011; Detmann et al., 2014).

Em condições tropicais, o BNR está positivamente associado à disponibilidade de nitrogênio (concentração dietética de PB e concentração de NAR), mas não sofre influência direta da digestibilidade da dieta (Detmann et al., 2014). Este comportamento indica que a deficiência dietética de nitrogênio é a causa da falta de equilíbrio no ambiente ruminal concernente ao balanço de nitrogênio.

Assim, considerando que a eficiência de utilização do nitrogênio está mais fortemente associada ao suprimento de nitrogênio, esta será então ampliada pela melhoria no status de nitrogênio no organismo animal com a utilização de suplementos proteicos (Detmann et al., 2014). Assim, elevar-se-á a proporção do nitrogênio total que é utilizada para fins anabólicos e a eficiência global de utilização da PM. Segundo Detmann et al. (2014), a hipótese de que a eficiência de uso do nitrogênio é ampliada pela melhoria no status de nitrogênio parece ser muito mais provável do que qualquer efeito direto do suprimento de PM via suplementos, pois incrementos nesta eficiência têm sido obtidos com o fornecimento de fontes nitrogenadas proteicas ou nãoproteicas (Egan e Moir, 1965; Costa et al., 2011c).

\section{CONCLUSÃO}

A suplementação proteica em bovinos manejados em pastagens tropicais durante o período de transição seca-águas não afeta o consumo voluntário de pasto, mas amplia com consumo voluntário total. Os principais efeitos da suplementação centram-se sobre ampliação no balanço de compostos nitrogenados e na eficiência de uso do nitrogênio como possível reflexo de melhorias do status de nitrogênio no organismo animal. Isto implica em mais ganho e melhor eficiência de uso dos nutrientes em sistemas de produção de bovinos em pastejo.

\section{AGRADECIMENTOS}

Ao Conselho Nacional de Desenvolvimento Científico e Tecnológico (CNPq), à Fundação de Amparo à Pesquisa do Estado de Minas Gerais (FAPEMIG) e ao Insituto Nacional de Ciência e Tecnologia em Ciência Animal (INCT-CA) pelo financiamento desta pesquisa.

\section{BIBLIOGRAFIA}

Acedo, T.S.; Paulino, M.F.; Detmann, E.; Valadares Filho, S.C.; Sales, M.F.L. e Porto, M.O. 2011 . Fontes protéicas em suplementos para novilhos no período de transição seca-águas: características nutricionais. Arq Bras Med Vet Zoo, 63: 895-904.

Batista, E.D. 2012. Suplementação nitrogenada ruminal e/ou abomasal em bovinos alimentados com forragem tropical de alta qualidade. 62f. Dissertação (Mestrado em Zootecnia). Universidade Federal de Viçosa. Viçosa.

Cecava, J.M.; Merchen, N.R.; Gay, L.C. and Berger, L.L. 1990. Composition of ruminal bacteria harvested from steers as influenced by dietary energy level, feeding frequency, and isolation techniques. $J$ Dairy Sci, 73: 2480-2488. 
Chizzotti, M.L.; Valadares Filho, S.C.; Valadares, R.F.D.; Chizzotti, F.H.M.; Campos, J.M.S.; Marcondes, M.I. e Fonseca, M.A. 2006. Consumo, digestibilidade e excreção de uréia e derivados de purinas em novilhas de diferentes pesos. Rev Bras Zootecn, 35: 1813-1821.

Costa, V.A.C.; Detmann, E.; Paulino, M.F.; Valadares Filho, S.C.; Henriques, L.T.; Carvalho, I.P.C. e Valente, T.N.P. 201 la. Consumo e dinâmica ruminal da fibra em detergente neutro em bovinos em pastejo no período das águas recebendo suplementação com nitrogênio não proteico e/ou proteína verdadeira. Rev Bras Zootecn, 40: 2805-2814.

Costa, V.A.C.; Detmann, E.; Paulino, M.F.; Valadares Filho, S.C.; Carvalho, I.P.C. e Monteiro, L.P. 2011 b. Consumo e digestibilidade em bovinos em pastejo durante o período das águas sob suplementação com fontes de compostos nitrogenados e de carboidratos. Rev Bras Zootecn, 40: 1788-1798.

Costa, V.A.C.; Detmann, E.; Paulino, M.F.; Valadares Filho, S.C.; Henriques, L.T. e Carvalho, I.P.C. 201 lc. Digestibilidade total e parcial e balanço nitrogenado em bovinos em pastejo no período das águas recebendo suplementos com nitrogênio não proteico e/ou proteína verdadeira. Rev Bras Zootecn, 40: 2815-2826.

Detmann, E.; Paulino, M.F. e Valadares Filho, S.C. 2010. Otimização do uso de recursos forrageiros basais. In: Simpósio de Produção de Gado de Corte, 7, 2010. Anais... SIMCORTE. Viçosa. pp.191-240.

Detmann, E.; Paulino, M.F.; Mantovani, H.C.; Valadares Filho, S.C.; Sampaio, C.B.; Souza, M.A.; Lazzarini, I. and Detmann, K.S.C. 2009. Parameterization of ruminal fiber degradation in low-quality tropical forage using Michaelis-Menten kinetics. Livest Sci, 126: 136-146.

Detmann, E.; Paulino, M.F.; Zervoudakis, J.T.; Valadares Filho, S.C.; Lana, R.P. e Queiroz, D.S. 2001. Suplementação de novilhos mestiços durante a época das águas: parâmetros ingestivos e digestivos. Rev Bras Zootecn, 30: 1340-1349.

Detmann, E.; Souza, M.A.; Valadares Filho, S.C.; Queiroz, A.C.; Berchielle, T.T.; Saliba, E.O.S.; Cabral, L.S.; Pina, D.S.; Ladeira, M.M. e Azevedo, J.A.G. (Eds.). 2012. Métodos para análise de alimentos. Suprema. Visconde do Rio Branco. Brasil. 214 pp.

Detmann, E.; Valente, E.E.L.; Batista, E.D. and Huhtanen, P. 2014. An evaluation of the performance and efficiency of nitrogen utilization in cattle fed tropical grass pastures with supplementation. Livest Sci, 162: 141-153.

Egan, A.R. 1965a. Nutritional status and intake regulation in sheep. III. The relationship between improvement of nitrogen status and increase in voluntary intake of low-protein roughages by sheep. Aust J Agri Res, 16: 463-472.

Egan, A.R. 1965b. The fate and effects of duodenally infused casein and urea nitrogen in sheep fed on a low-protein roughage. Aust $J$ Agri Res, 16: 169-177.
Egan, A.R. and Moir, R.J. 1965. Nutritional status and intake regulation in sheep. I. Effects of duodenally infused single doses of casein, urea, and propionate upon voluntary intake of a low-protein roughage by sheep. Aust J Agri Res, 16: 437-449.

Figueiras, J.F.; Detmann, E.; Paulino, M.F.; Valente, T.N.P.; Valadares Filho, S.C. and Lazzarini, I. 2010. Intake and digestibility in cattle under grazing supplemented with nitrogenous compounds during dry season. Rev Bras Zootecn, 39: 1303-1312.

Hennessy, D.W. and Nolan, J.V. 1988. Nitrogen kinetics in cattle fed a mature subtropical grass hay with and without protein meal supplementation. Aust J Agri Res, 39: 1135-1150.

Illius, A.W. and Jessop, N.S. 1996. Metabolic constraints on voluntary intake in ruminants. J Anim Sci, 74: 3052-3062.

Lazzarini, I. 2011. Desempenho nutricional de bovinos em pastejo durante os períodos de seca e águas suplementados com compostos nitrogenados e/ou amido. 66f. Tese (Doutorado em Zootecnia). Universidade Federal de Viçosa. Viçosa.

Marini, J.C. and Van Amburgh, M.E. 2003. Nitrogen metabolism and recycling in Holstein heifers. J Anim Sci, 81: 545-552.

Nascimento, M.L.; Paulino, M.F.; Detmann, E.; Valadares Filho, S.C.; Porto, M.O. e Sales, M.F.L. 2009. Fontes de energia em suplementos múltiplos para recria de novilhos mestiços em pastejo durante o período de transição seca/águas: desempenho produtivo e características nutricionais. Rev Bras Zootecn, 38: 1121-1132.

National Research Council - NRC. 1985. Ruminant nitrogen usage. Academic Press. Washington, DC. USA. 138 pp.

Ørskov, E.R. 1988. Nutrición proteica de los rumiantes. Editora Acribia. Zaragoza. Espanha. 178 pp.

Rufino, L.M.A. 2011 . Suplementação nitrogenada ruminal e/ou abomasal em bovinos alimentados com forragem tropical de baixa qualidade. 2011 . 44f. Dissertação (Mestrado em Zootecnia). Universidade Federal de Viçosa. Viçosa.

Sales, M.F.L.; Paulino, M.P.; Valadares Filho, S.C.; Figueiredo, D.M.; Porto, M.O. and Detmann, E. 2011. Supplementation levels for growing beef cattle grazing in the dry-rainy transition season. Rev Bras Zootecn, 40: 904-911.

Sampaio, C.B.; Detmann, E.; Paulino, M.F.; Valadares Filho, S.C.; Souza, M.A.; Lazzarini, I.; Paulino, P.V. and Queiroz, A.C. 2010. Intake and digestibility in cattle fed low-quality tropical forage and supplemented with nitrogenous compounds. Trop Anim Health Pro, 42: 1471-1479.

Ushida, K.; Lassalas, B. and Jouany, J.P. 1985. Determination of assay parameters for RNA analysis in bacterial and duodenal samples by spectrophotometry. Influence of treatment and preservation. Reprod Nutr Dev, 25: 1037-1046.

Van Soest, P.J. 1994. Nutritional ecology of the ruminant. 2 ed. Cornell University Press. Ithaca, NY. USA. 476 pp. 